\title{
Analysis of Tests Evaluating Sport Climbers' Strength and Isometric Endurance
}

\author{
by \\ Mariusz Ozimek ${ }^{1}$, Robert Staszkiewicz ${ }^{2}$, Robert Rokowski ${ }^{3}$, Arkadiusz Stanula ${ }^{4}$
}

The present study was designed to determine which types of specific tests provide an effective evaluation of strength and endurance in highly trained competitive sport climbers. The research process consisted of three basic components: the measurement of selected somatic characteristics of the climbers, the assessment of their physical conditioning, and a search for correlations between the anthropometric and "conditioning" variables on the one hand, and climber's performance on the other. The sample of subjects consisted of 14 experienced volunteer climbers capable of handling $7 a-8 a+/ b$ on-sight rock climbing grades. The strongest correlations (Spearman's rank) were found between climber's competence and the relative results of the finger strength test $(r=0.7)$; much lower, but still statistically significant coefficients were found between the level of competence and the results of the muscle endurance tests ( $r=$ 0.53 - 0.57). Climbers aspiring to attain an elite level must have strong finger and forearm muscles, but most of all, they must be capable of releasing their potential during specific motor capability tests engaging these parts of the body. The forearm muscles of elite climbers must also be very resistant to fatigue. Since highly trained athletes vary only slightly in body mass, this variable does not have a major effect on their performance during strength and endurance tests.

Key words: rock climbing, training, physical performance, biomechanics.

\section{Introduction}

Sport climbing is becoming increasingly popular. Climbing can be performed for recreational purposes or as a competition, on both natural rocks and indoors. The growing interest in this form of physical activity makes it easier to organize sports events that quite naturally, involve the implementation of relevant training methods that prepare climbers to compete and win. As in any other sport discipline, the factors determining top performance must be precisely established to increase the effectiveness of athlete recruitment, selection and training. Numerous practitioners along with theoreticians specializing in sports training indicate that high performance in climbing is mainly based on strength and endurance (España-Romero et al., 2009; Grant et al., 2001; MacLeod et al., 2007; Schweizer and Furrer, 2007). However, the importance of other factors in determining elite performance has also been noted (Mermier et al., 2000).

To assess muscular strength in humans, dynamometer tests (requiring the use of appropriate measuring devices) and specific tests (measuring motor abilities) can be used (Watts et al., 2008). A review of the literature shows that both of these types of tests have been applied to investigate climbers' strength. Endurance is usually determined by maximal exercise tests,

\footnotetext{
1 - Department of Track end Fields Sports, University School of Physical Education, Cracow, Poland.

2 - Department of Biomechanics, University School of Physical Education, Cracow, Poland.

3 - Department of Qualified Tourism and Mountaineering, University School of Physical Education, Cracow, Poland.

4 - Department of Sports Training, The Jerzy Kukuczka Academy of Physical Education, Katowice, Poland.
} 
which measure the time the subject needs to attain grip strength equal to a predetermined percentage of maximum strength (Ferguson and Brown, 1997; MacLeod et al., 2007; Sheel, 2004; Watts, 2004). Some specific tests have the subjects hang from ledges of different widths until volitional exhaustion (MacLeod et al., 2007; Rokowski and Tokarz, 2007).

Analysis of the available literature indicates a great need for scientific research focused on training of climbers (Amca et al., 2012; Philippe et al., 2012). Thus, an increasing number of studies on the physiology, biomechanics and biochemistry of this sports discipline may be observed. Moreover, there is a lack of literature with respect to testing of motor abilities. Most of the studies have described some state of the climber's body that is, however, difficult to evaluate without attending a well-equipped laboratory. Thus, a practical application of the research results is rather complex and often impossible without the assistance of scientists. Consequently, coaches and athletes are left alone with large amounts of data from which they need to make an optimal choice for training purposes.

Previous research shows that specific and dynamometer tests applied to elite climbers result in different assessments of their motor abilities. In a Rokowski and Tokarz's (2007) study, the results of the dynamometer strength tests were unrelated to subjects' climbing performance, but the results of the specific test requiring subjects carrying a maximum weight to hang from a ledge $2.5 \mathrm{~cm}$ in width were strongly correlated with their climbing performance. This difference naturally raises the question of why the results of the dynamometer tests were weakly correlated with climber's performance, unlike the results of specific tests. The explanation lies possibly in the technical limitations of the measurements made with dynamometers and in the unique nature of climber's movements. There are a limited number of grip configurations allowing maximum grip strength to be measured with the dynamometer, some of which are never used on the climbing wall. This indicates a need for further research to remove the doubts regarding whether ledge tests truly measure climbers' endurance and whether ledges of different widths should be used; another issue to discuss is how muscle strength influences test results.
Since the main force that climbers must manage is that of their own body weight (Ruchlewicz et al., 1997), many studies make a point of climbers having the appropriate body build (Giles et al., 2006; Magiera et al., 2013; Michailov et al., 2009). The hypothesis that the body mass of elite athletes has a major impact on their performance in motor abilities tests appears to be well-founded. There are also reasons to believe that climbing-specific strength of individual climbers is correlated with their ability to increase muscular strength. In the literature, researchers refer to contact strength, a term unique to climbing, which determines an athlete's ability to grasp a hold with maximum strength on contact (Fanchini et al., 2013; Schweizer, 2001).

This study aimed to establish which types of specific tests could be effectively used in assessing muscular strength and endurance of highly trained sport climbers. The authors attempted to answer the following questions: Do dynamometer tests and specific tests measure the same aspects of muscular strength and endurance? If yes, how are laboratory tests and specific field tests similar and what makes them different? The second part of the study focused on establishing whether basic anthropometric variables of climbers had an effect on the measurement of their motor abilities.

\section{Material and Methods}

\section{Participants}

Fourteen male climbers capable of handling 7a- $8 \mathrm{a}+/ \mathrm{b}$ on-sight grades volunteered to participate in the study. Their mean $( \pm$ SD) age was $26.6 \pm 5.6$ years, body height $177.4 \pm 4.5 \mathrm{~cm}$ and body mass $74.4 \pm 5.1 \mathrm{~kg}$. All participants were advised of the purpose and scope of the study, as well as of any negative impacts it might involve, orally and in writing. The research project was approved by the Bioethics Commission at the Local Medical Chamber in Cracow.

\section{Procedures}

The research activities related to this study were performed in the facilities of the Academy of Physical Education in Cracow (APE Cracow), partly at the Department of Biomechanics (laboratory tests) and partly in the gym (motor ability tests).

To encourage the climbers to perform as well as they could, the measurements included 
elements of competition. The sequence of measurements was implemented in strict accordance with the research protocol: climbers were assessed for body build (height and mass) before their motor abilities were tested. During the laboratory tests and the motor ability tests, strength tests were performed before endurance tests. The break between tests performed in the biomechanics laboratory and those in the gym was one week.

Climbers' strength was assessed during three trials. The first of them, measuring maximal isometric grip strength (FMAX), used a hand dynamometer (Hottinger Baldwin Messtechnik $\mathrm{GmbH}$, Darmstaddt, Germany) with linearly adjustable resistance points that was therefore suitable for all subjects regardless of their hand size. The device complied with the ISO 6789 regulations, according to which the minimization of measurement error of the strength converter to $1 \%$ of the true value was required. The subjects were asked to shape their hand into a hook grip with an opposing thumb so that the resistance of the dynamometer acted on their intermediate phalanges (fingers II-V) and the ball of the thumb (I). During the measurements, the subjects comfortably rested their forearms on a support with adjustable height. This setup was used to measure maximum grip strength of their right and left hands (FMAX R, FMAX L) in Newtons $[\mathrm{N}]$; the results were then divided by the subject's body mass to calculate their relative strength (FW R, FW L) expressed in N/kg.

Picture 1 shows the procedure applied to measure strength of the fingers. The subjects had to grip a $2.5 \mathrm{~cm}$ wide ledge and to hang vertically with an additional maximum load attached to their hip belt. The grip was performed with only four fingers of each hand (without thumbs) and with hands shoulders' width apart. The subject was required to maintain this position for $3 \mathrm{~s}$. Each attempt started with adding a load of $40 \mathrm{~kg}$, and in the consecutive attempts, the load was increased by $5 \mathrm{~kg}$ each time. When the subject was not able to remain in the position for $3 \mathrm{~s}$, the attempt was stopped, and in the following trials, the additional load was reduced by $1-2 \mathrm{~kg}$ to determine the individual maximum load the subject was able to hold. The rest periods between subsequent attempts lasted $5 \mathrm{~min}$. The results of this test were recorded as absolute values, a sum of body mass and the additional load [kg], and relative strength, i.e., without body mass (Rokowski and Tokarz, 2007). The results of the test in absolute and relative values were referred to as LEDGE 1 and LEDGE 2, respectively.

On the same day, the subjects performed a test assessing strength of their arm muscles (Picture 2). They were asked to do a pull-up bringing their chin over the bar, with the maximum weight they could lift attached to their harness. The overhand grip was required and the hands were positioned at shoulders' width. The results of this test were recorded (with an accuracy of $1 \mathrm{~kg}$ ) in both absolute and relative values (Ferguson and Brown, 1997); for the purpose of later analysis, these values were further referred as BAR 1 and BAR 2, respectively.

The speed of action of the climbers' finger flexors was measured at the same diagnostic station as previously grip strength. The position of the hand on the dynamometer was also the same. The subjects performed an isometric muscle contraction to achieve maximum tension of the muscles as fast as they could. The force values were recorded and the data were used to calculate the rate of force development. Of the indicators calculated with $F=f(t)$, only maximum muscle force development values of the left and right hand (F'MAX L and F'MAX $R$, respectively) expressed as $\mathrm{N} / \mathrm{s}$ were used in further analysis (Ruchlewicz et al., 1997).

The group of tests assessing climbers' muscle endurance consisted of laboratory tests and specific motor tests. Muscle resistance to fatigue was measured in subjects as they performed prolonged isometric muscle contractions by squeezing an adjustable hand dynamometer. The subjects were instructed to maintain muscle contractions at $50 \%$ of their maximum grip strength until failure. They were able to follow their grip strength variations in all trials as signals generated by the dynamometer were displayed on a computer monitor they could see. With this setup, they were able to adjust the force they applied by increasing or decreasing grip strength as needed. The outcome of this laboratory test was expressed as grip duration in seconds; in further analysis, it was referred as t FMAX50\%.

Subjects' endurance (the resistance of muscles to fatigue) was also examined with 
specific motor tests. The first of them (HANG 1) required the subject to hang from a $2.5 \mathrm{~cm}$ wide ledge. The second test (HANG 2) the only difference was that a $4 \mathrm{~cm}$ ledge was used. In both tests, the subjects had to grip the ledge with four fingers of each hand (the thumb left disengaged), hands held at shoulders' width, upper extremities straight, and they were required to hang vertically as long as they could (until failure) (Ferguson and Brown, 1997). The outcome of these tests was the length of the time that they could maintain this position, measured with an accuracy of $1 \mathrm{~s}$.

In the experiment, two of the tests measuring muscle resistance to fatigue used the pull-up bar. The first of them (HANG) required the subject to hold the bar with an overhand grip and to hang from it until volitional exhaustion. The result of this test was expressed by the time the subject could hold on. In the second test (PULL UPS), the maximum number of pull-ups completed by the subject was recorded, but for a pull-up to be credited, it had to be performed in accordance with the International Physical Fitness Test rules (Quaine and Vigouroux, 2004).

\section{Statistical analysis}

After the results of the tests were processed with descriptive statistics (the arithmetic mean and measures of variance), rank correlation coefficients were calculated (Pearson's r) to determine whether particular structural and functional variables were correlated with each other. Cluster analysis was applied to observe which groups were formed at particular levels. Finally, to determine strength of the relationships between the values of all investigated variables and climbers' competence, the Spearman's rank correlation was used. The level of significance was set at $p \leq 0.05$. The calculations were performed with the Statistica 10 statistical software package (StatSoft, USA).

\section{Results}

Table 1 provides descriptive statistics for all variables measured in the studied climbers. Small differences in body mass (range from 61 to $69 \mathrm{~kg})$ and a low coefficient of variance $(\mathrm{CV}=$ $3.5 \%$ ) showed that the sample of climbers was very homogenous in that respect. The results of the strength tests divided them into three groups characterized by similarly distributed results: the dynamometer tests (FMAX, FW), the PULL UPS tests (BAR 1 and BAR 2) and the test with the 2.5 $\mathrm{cm}$ ledge. The $\mathrm{CV}$ values calculated for these three groups were 10, 7 and more than $20 \%$, respectively. With regard to the endurance tests, pull-ups on the bar were the only test to have a $\mathrm{CV}$ below $15 \%$. The mean time of maintaining grip force equal to half of its maximum value (t FMAX 50\%) was below 2 minutes; however, some climbers could continue for more than 3 minutes. In the endurance tests with the bar, the climbers could hang vertically for an average of 4 minutes (HANG) and the mean number of pullups they could do exceeded 22.

The cluster analysis formed two main groups of tests: one consisting of tests measuring various aspects of muscle strength and speed, and the other comprising tests investigating muscle endurance. Among the "strength tests", the results of LEDGE 1 and LEDGE 2 were most similar. On the upper level in the bottom section of the diagram, they were positioned with the results of the dynamometer tests measuring absolute and relative grip strength and muscle force development. In the upper section of the diagram, the results of LEDGE 1 and LEDGE 2 connected with the results of BAR 1 and BAR 2, which showed absolute and relative arm strength. In the second group of tests (evaluating muscle endurance), the results of HANG 1 and HANG 2 were closely related. On the upper level, they cooccurred with the results obtained from the HANG test. The results of both identified groups of tests (measuring different aspects of muscle strength and endurance) clearly clustered together in the mid-section of the diagram. In the upper section, they were located with the results of the PULL UP test. Still higher in the taxonomic tree, in the upper section of the diagram, there were body mass values. At the highest level, they were together with the results of the dynamometer test requiring the subjects to maintain $50 \%$ of FMAX until volitional exhaustion.

An enhancement to the above analysis was provided by the results of Pearson's rank correlations (Table 2). The coefficients of the rank correlation (Table 3) for LEDGE 1 and LEDGE 2 were very high $(r=0.99)$. Analysis of the correlations between the results of the dynamometric (strength) tests and those yielded by the test measuring strength of the fingers in the specific position of the hand on the hold 
(LEDGE 1 and 2) did not show any statistically significant coefficients. The same applied to the LEDGE 1 and 2 strength tests and the arm strength tests (BAR 1 and 2) - the results of the ledge and PULL UPS bar tests were positively correlated, but the correlations were significant in one case only. The results of the muscle endurance test "maintaining 50\% of FMAX" were not found to be significantly related to the results of any other test.

Spearman's rank correlation coefficients (Table 4) between climber's competence and the results of the finger strength tests (LEDGE 1 and 2 ) and of the test measuring resistance to fatigue of the isometrically contracted forearm muscles (HANG 1, 2 and HANG) were statistically significant. The strongest correlations were found between climber's competence and the relative results of the finger strength test $(r=0.7)$; much weaker, but still significant coefficients were found between the level of competence and the results of the muscle endurance tests ( $r=0.53-$ 0.57). Especially noteworthy was a relatively high, although statistically non-significant coefficient of correlation between climber's competence and the results of the PULL UPS test $(r=0.48)$.

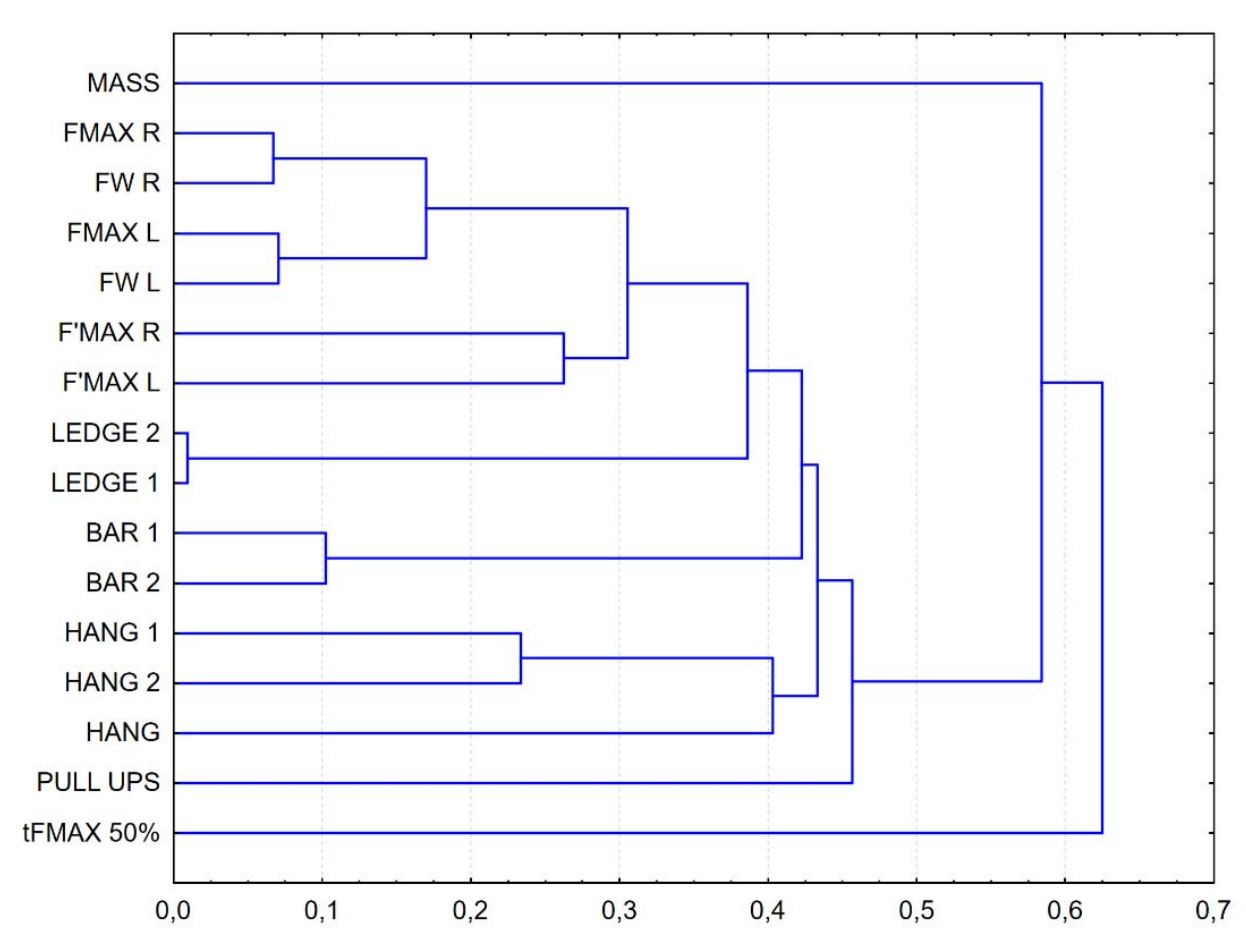

Figure 1

The diagram of connections between the 17 variables characterizing the climbers.

MASS - body mass [kg]; FMAX R, FMAX L - maximal grip strength (right and left hands) [N];

$F W R, F W L$ - relative grip strength (right and left hands) [N/kg];

F'MAX R, F'MAX L-maximum muscle force development (right and left hands) [N/s];

LEDGE 1 - maximal strength of the fingers (hang from a $2.5 \mathrm{~cm}$ wide ledge) [ $\mathrm{kg}]$;

LEDGE 2 - relative strength of the fingers (hang from a $2.5 \mathrm{~cm}$ wide ledge) $[\mathrm{kg} / \mathrm{kg}]$;

BAR 1 - maximal strength of arm muscles (hang from a bar) $[\mathrm{kg}]$;

BAR 2 - relative strength of arm muscles (hang from a bar) $[\mathrm{kg} / \mathrm{kg}]$;

HANG 1 - muscle endurance (hang from a $2.5 \mathrm{~cm}$ wide ledge) [s];

HANG 2 - muscle endurance (hang from a $4.0 \mathrm{~cm}$ wide ledge) [s];

HANG - muscle endurance (hang from a bar) [s]; PULL UPS - maximum number of pull-ups [n];

$\boldsymbol{t}$ FMAX 50\% - muscle endurance (maintain a dynamometer grip force at 50\% of Fmax) [s]. 


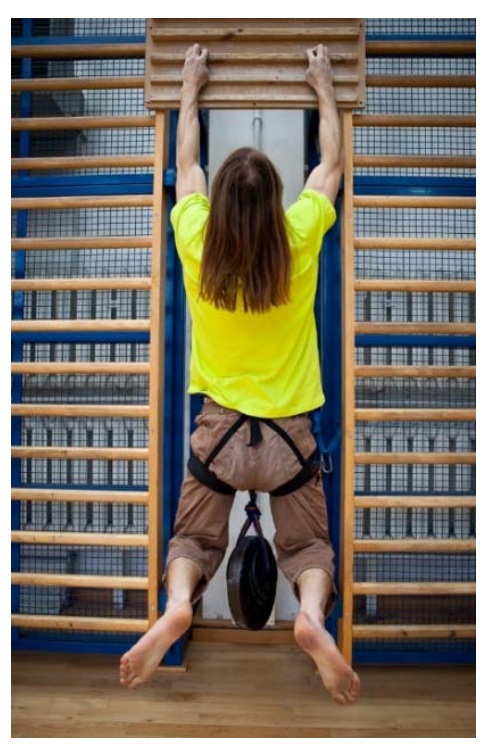

Picture 1

The specific test of finger strength (refer to abbreviation: LEDGE 1, LEDGE 2, HANG 1, HANG 2).

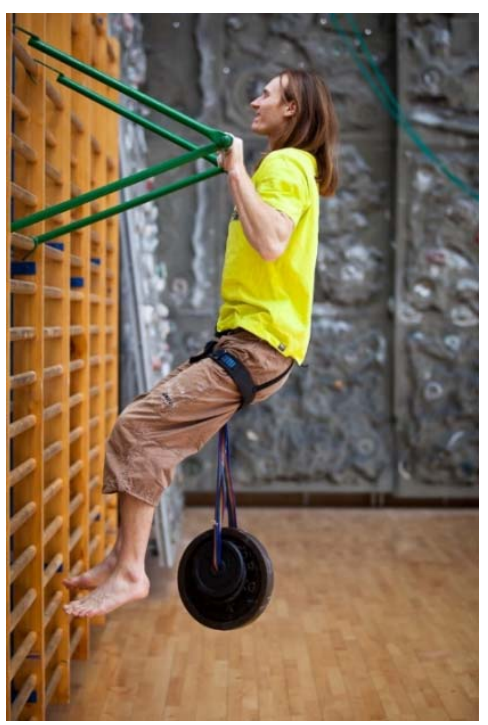

Picture 2

The arm strength test (refer to abbreviation: BAR 1, BAR 2, PULL UPS). 


\section{Table 1}

Statistical characteristics of somatic variables, muscle strength and endurance in the studied climbers $(n=14)$

\begin{tabular}{|c|c|c|c|c|c|}
\hline Variables & m.u. & Mean \pm SD & $\min$ & $\max$ & $\mathrm{CV}$ \\
\hline MASS & $\mathrm{kg}$ & $65.42 \pm 2.28$ & 61 & 69 & 3.5 \\
\hline FMAX R & $\mathrm{N}$ & $655 \pm 62.5$ & 553 & 772 & 10.0 \\
\hline FW R & $\mathrm{N} / \mathrm{kg}$ & $10.01 \pm 0.96$ & 8.5 & 12.16 & 9.6 \\
\hline FMAX L & $\mathrm{N}$ & $640 \pm 62.0$ & 567 & 754 & 9.7 \\
\hline FW L & $\mathrm{N} / \mathrm{kg}$ & $9.78 \pm 0.91$ & 8.73 & 11.72 & 9.3 \\
\hline LEDGE 1 & $\mathrm{~kg}$ & $137.32 \pm 31.4$ & 91 & 166 & 22.9 \\
\hline LEDGE 2 & $\mathrm{~kg} / \mathrm{kg}$ & $2.09 \pm 0.46$ & 1.49 & 2.5 & 22.0 \\
\hline BAR 1 & $\mathrm{~kg}$ & $111 \pm 8.56$ & 96 & 132 & 7.7 \\
\hline BAR 2 & $\mathrm{~kg} / \mathrm{kg}$ & $1.69 \pm 0.12$ & 1.55 & 2 & 7.1 \\
\hline $\mathrm{F}^{\prime} \mathrm{MAX} \mathrm{R}$ & $\mathrm{N} / \mathrm{s}$ & $5549 \pm 1369$ & 3280 & 8223 & 24.7 \\
\hline$F^{\prime} M A X L$ & $\mathrm{~N} / \mathrm{s}$ & $4942 \pm 1529$ & 3420 & 7834 & 30.9 \\
\hline t FMAX 50\% & $\mathrm{s}$ & $103 \pm 33.9$ & 71.5 & 189 & 33.0 \\
\hline HANG 1 & $\mathrm{~s}$ & $84.9 \pm 19.8$ & 50 & 133 & 23.4 \\
\hline HANG 2 & s & $108.6 \pm 32.4$ & 65 & 163 & 29.9 \\
\hline HANG & $\mathrm{s}$ & $240.7 \pm 71.8$ & 148 & 340 & 29.8 \\
\hline PULL UPS & $\mathrm{n}$ & $22.9 \pm 3.4$ & 17 & 30 & 14.7 \\
\hline
\end{tabular}

Statistical significance: $\neq p<0.001,+p<0.01,{ }^{*} p<0.05$

MASS - body mass [kg]; FMAX R, FMAX L-maximal grip strength (right and left hands) [N];

$F W R, F W L$ - relative grip strength (right and left hands) [N/kg];

$F^{\prime} M A X R, F^{\prime} M A X L$ - maximum muscle force development (right and left hands) [N/s];

LEDGE 1 - maximal strength of the fingers (hang from a $2.5 \mathrm{~cm}$ wide ledge) [kg];

LEDGE 2 - relative strength of the fingers (hang from a $2.5 \mathrm{~cm}$ wide ledge) $[\mathrm{kg} / \mathrm{kg}]$;

BAR 1 - maximal strength of arm muscles (hang from a bar) [kg];

BAR 2 - relative strength of arm muscles (hang from a bar) $[\mathrm{kg} / \mathrm{kg}]$;

HANG 1 - muscle endurance (hang from a $2.5 \mathrm{~cm}$ wide ledge) [s];

HANG 2 - muscle endurance (hang from a $4.0 \mathrm{~cm}$ wide ledge) [s];

HANG - muscle endurance (hang from a bar) [s]; PULL UPS - maximum number of pull-ups [n];

t FMAX 50\% - muscle endurance (maintain a dynamometer grip force at 50\% of Fmax) [s]. 
Table 2

Pearson product moment correlations $(r)$ between variables

\begin{tabular}{|c|c|c|c|c|c|c|c|c|}
\hline Variables & MASS & FMAX R & FW R & FMAX L & FW L & $\mathrm{F}^{\prime} \mathrm{MAX} \mathrm{R}$ & $\mathrm{F}^{\prime} \mathrm{MAX} \mathrm{L}$ & $\begin{array}{c}\text { t FMAX } \\
50 \%\end{array}$ \\
\hline FMAX R & 0.32 & & & & & & & \\
\hline FW R & -0.04 & $0.93 \ddagger$ & & & & & & \\
\hline FMAX L & 0.32 & $0.83 \ddagger$ & $0.76^{*}$ & & & & & \\
\hline FW L & -0.05 & $0.76^{*}$ & $0.82 \ddagger$ & $0.93 \ddagger$ & & & & \\
\hline $\mathrm{F}^{\prime} \mathrm{MAX} \mathrm{R}$ & 0.09 & 0.35 & 0.33 & 0.48 & 0.46 & & & \\
\hline$F^{\prime} M A X L$ & 0.21 & 0.46 & 0.40 & $0.69^{*}$ & $0.64^{*}$ & $0.74^{*}$ & & \\
\hline $\begin{array}{l}\text { t FMAX } \\
50 \%\end{array}$ & 0.13 & -0.06 & -0.11 & 0.02 & -0.04 & -0.22 & 0.14 & \\
\hline LEDGE 1 & 0.42 & 0.40 & 0.27 & 0.61 & 0.48 & 0.33 & 0.52 & -0.01 \\
\hline LEDGE 2 & 0.30 & 0.39 & 0.30 & $0.60^{*}$ & 0.52 & 0.32 & 0.50 & -0.03 \\
\hline HANG 1 & 0.05 & 0.09 & 0.08 & -0.05 & -0.05 & -0.46 & -0.14 & 0.28 \\
\hline HANG & -0.24 & -0.20 & -0.12 & -0.05 & 0.03 & 0.08 & 0.01 & 0.22 \\
\hline HANG 2 & -0.23 & -0.33 & -0.25 & -0.37 & -0.29 & -0.52 & -0.27 & 0.38 \\
\hline BAR 1 & 0.41 & 0.44 & 0.30 & 0.45 & 0.31 & 0.34 & 0.41 & -0.13 \\
\hline BAR 2 & -0.04 & 0.33 & 0.35 & 0.34 & 0.36 & 0.32 & 0.34 & -0.20 \\
\hline PULL UPS & -0.36 & 0.26 & 0.41 & 0.06 & 0.20 & 0.07 & 0.13 & 0.01 \\
\hline
\end{tabular}

Statistical significance: $\neq p<0.001,+p<0.01,{ }^{*} p<0.05$

Table 3

Spearman's rank correlation coefficients $(r)$ between variables

\begin{tabular}{|c|c|c|c|c|c|c|c|}
\hline Variables & LEDGE 1 & LEDGE 2 & HANG 1 & HANG & HANG 2 & BAR 1 & BAR 2 \\
\hline LEDGE 2 & $0.99 \ddagger$ & & & & & & \\
\hline HANG 1 & 0.28 & 0.31 & & & & & \\
\hline HANG & 0.51 & $0.57^{*}$ & 0.32 & & & & \\
\hline HANG 2 & 0.13 & 0.18 & $0.77 \dagger$ & $0.60^{*}$ & & & \\
\hline BAR 1 & $0.58^{*}$ & $0.56^{*}$ & 0.14 & 0.09 & -0.04 & & \\
\hline BAR 2 & 0.44 & 0.47 & 0.13 & 0.22 & 0.07 & 0.90 & \\
\hline PULL UPS & 0.12 & 0.18 & 0.33 & 0.15 & 0.29 & 0.34 & $0.54^{*}$ \\
\hline
\end{tabular}

Statistical significance: $\neq p<0.001,+p<0.01,{ }^{*} p<0.05$ 
Table 4

Coefficient rank size of climber's competence with body mass, motor effects of strength and endurance character $(n=14)$

\begin{tabular}{|c|c|c|c|}
\hline Variables & $\mathrm{R}$ & Variables & $\mathrm{R}$ \\
\hline MASS & -0.23 & LEDGE 2 & $0.70 \ddagger$ \\
\hline FMAX R & -0.00 & LEDGE 1 & $0.53^{*}$ \\
\hline FW R & 0.02 & HANG 1 & $0.54^{*}$ \\
\hline FMAX L & 0.08 & HANG & $0.56^{*}$ \\
\hline FW L & 0.01 & HANGS 2 & 0.57 \\
\hline$F^{\prime} M A X R$ & -0.05 & BAR 1 & -0.08 \\
\hline$F^{\prime} M A X L$ & 0.32 & BAR 2 & 0.17 \\
\hline t FMAX 50\% & -0.12 & PULL UPS & 0.48 \\
\hline
\end{tabular}

\section{Discussion}

The cluster and correlation analysis of the results of the above tests provided answers to the question of how useful a motor test scan could be in evaluating muscle strength and endurance in sport climbers. A literature review has shown that while some researchers use dynamometers to assess muscle strength variables, others prefer specific motor tests. Unlike the results obtained during specific trials (Ferguson and Brown, 1997), those provided by dynamometer tests have not been significantly correlated with athlete's competence, which casts some doubts as to whether dynamometer tests and specific conditioning tests, such as hanging from a ledge, measure the same aspects of muscle strength. An explanation of this inconsistency can be sought in the technical limitations of the standard measurement devices. Laboratory tests utilizing standard dynamometers very rarely replicate the true conditions of a climbing competition, especially regarding the configuration of the climber's wrists and fingers during grips (Booth et al., 1999; Giles et al., 2006). This fact makes them less useful for assessing muscle strength, particularly in elite climbers. The outcomes of this research fully support this observation, as they showed that although the dynamometric and specific tests were part of the same group of strength tests, their results were not significantly correlated. The reasons for these results can be identified with an analysis of the grips. Unlike the ledge test, the grip strength test actively engages climber's muscles and the thumb acting in opposition to the fingers. Moreover, the specific tests engage many more muscle groups (the whole group of antigravitational muscles moving the upper extremities) than the dynamometer tests. Finally, the muscles that the dynamometric grip activates remain in an isometric contraction. In contrast, the muscle work required in a climber hanging from a ledge must be more effective because the engaged muscles must cope with 
gravity-induced stretching. The mechanism underlying this muscle reaction is explained in Staszkiewicz et al. (2002). All these findings provide grounds for concluding that the two types of tests differ from each other: the measurement of grip strength is not specific in determining the performance of elite climbers, although it is a useful tool for evaluating the general population or for application in crosssectional studies. In elite climbing, a variable that should be considered relates to specific grips, especially the ones using distal phalanges. Moreover, an evaluation of elite climbers can be performed on the basis of specific tests.

The assumptions made in this study were that climber's performance and the results of the arm strength tests (BAR 1 and 2) would correlate and that some affinity between the results of the pull-up bar and ledge tests performed with additional loads could be expected. As observed, the assumption was incorrect. The motor tests (LEDGE 2 and BAR 2) were very similar, their results, as presented in the tree diagram, were positioned close to each other, and both measured relative strength of the arms, but they were indeed different. The result of the ledge test is determined by strength of the finger flexors, whereas in the PULL UPS test, the elbow flexors are most significant. More arguments in support of this observation can be found in Watts et al. (1993). Evaluating the bioelectric potential of the flexor digitorum superficialis and the brachioradialis, the researchers established that both muscles were active in a subject doing a pullup engaging the four fingers of each hand and that the bioelectrical potential in the flexor digitorum superficialis was greater.

All available studies and practical experience indicate that endurance is important in competitive sport climbing (España-Romero et al., 2009; Ferguson and Brown, 1997; Magiera et al., 2013). The endurance tests applied in this study required the climbers to hang from a bar, a $2.5 \mathrm{~cm}$ ledge and a $4 \mathrm{~cm}$ ledge until volitional failure (HANG, HANG 1 and 2, respectively). The duration of the trial was an indication of the subject's resistance to fatigue. It was not surprising to find that the results of both ledge tests $(r=0.77)$ were very strongly correlated. At the same time, the duration of the bar test (HANG) was significantly correlated only with the time of the $4 \mathrm{~cm}$ ledge test (HANG 2). These findings can be explained by referring to the different grip sizes. While the ledge tests engage distal phalanges of the last four fingers, the bar test requires the motor apparatus of the whole hand to be activated, which means that the ledge tests appear to measure muscle resistance to fatigue in small grips and the bar test to measure resistance to fatigue in larger grips. Since climbing difficulty inherently concerns the types of grips a route involves and because the most difficult routes that only elite climbers can complete have holds requiring many small grips, it becomes quite clear why the length of time climbers could hang from the ledge differentiated them from each other and why this time was correlated with their competence.

The necessity for laboratory tests to replicate actual climbing requirements and the objective problems with meeting this demand seem to be the main reason why the results of the test requiring subjects to maintain a dynamometer grip force at $50 \%$ of FMAX were not directly related to the results of the endurance tests. This ambiguity of results has also been indicated in Mermier et al. (2000). In their study it was found that climbers were able to generate higher grip force values than non-athletes, although the two groups did not significantly differ in the length of time they could maintain the required force. The outcomes of this experiment additionally show that the results of the test were not related to climber's competence. All these findings and the aforementioned limited value of grip strength tests in climbing provide grounds for not using the grip force test to evaluate muscle endurance in climbers.

The last element of our study on muscle endurance concerns the results of the pull-up test. When applied to the general population, the test accurately measures strength of subjects' upper extremities, as most of them do not have appropriately strong arms to complete the pull-up test easily; additionally, the test allows to observe how particular individuals differ in that respect. In elite climbers, relative strength of the upper extremities is much greater, and thus the interpretation of the test's results is not so simple. Not only can they perform more repetitions, but the number of pull-ups completed differs only slightly between individual climbers (Table 1). 
The results of the analyses indicate that the pullup test has a hybrid character (requiring both strength and endurance). Its results in the dendrogram are situated close to the results of the strength and endurance tests, which implies that in elite climbers, the test measures the endurance of arm muscles. Although the number of pull-ups the studied climbers could complete on the bar and their performance were not significantly correlated, it is still important to remember that the functional status of the arm musculature is vital in this sport. The results of other studies (Booth et al., 1999) lead to the same conclusion, as they clearly point to much greater strength endurance of the arms of climbers compared to non-climbers.

Muscular strength and endurance are evaluated using tests measuring their absolute and relative values. It can be presumed that the absolute result of the strength test in particular may heavily depend on subject's body mass. Some evidence in support of this conclusion can be found in studies conducted with athletes (MacLeod et al., 2007; Schöffl et al., 2006) and nonathletes. However, in competitive sport climbers, this relationship is somewhat different. The main resistance force they must cope with while climbing comes from their body weight (Quaine and Vigouroux, 2004; Ruchlewicz et al., 1997); therefore, they need to demonstrate high values of relative strength, defined as the ratio between maximum strength and body mass (Michailov et al., 2009). In this experiment, the rank correlation coefficients between the results of muscle strength and muscle endurance tests and climbers' body mass were low. This finding was probably caused by the very small variance in body mass (a CV of approximately $3.5 \%$ ) and the climbers being very similar in their skills. The aforementioned small range in body mass values can probably be attributed to the nature of the training process and the related length of climbing experience, as well as to the specific selection of individuals for this sport. No subjects in the study had body mass greater than $70 \mathrm{~kg}$ and the difference between the heaviest and the lightest climber only slightly exceeded $10 \%(8 \mathrm{~kg})$. In other studies (Rokowski and Tokarz, 2007; Ruchlewicz et al., 1997), elite climbers were found to have a similar body build, which appears to clearly indicate that this morphological feature is not a major factor in differentiating climbers in terms of strength and endurance.

\section{Acknowledgements}

This scientific work was financed by one of the projects of the Ministry of Science and Higher Education entitled The Development of Academic Sport for the period 2015-2018, Project No. 01753 N RSA3.

\section{References}

Amca AM, Vigouroux L, Aritan S, Berton E. Effect of hold depth and grip technique on maximal finger forces in rock climbing. J Sports Sci, 2012; 30: 669-677

Booth J, Marino F, Hill C, Gwinn T. Energy cost of sport rock climbing in elite performers. Br J Sports Med, 1999; 33: 14-18

España-Romero V, Ortega Porcel FB, Artero EG, Jiménez-Pavón D, Gutiérrez Sainz A, Castillo Garzón MJ, Ruiz JR. Climbing time to exhaustion is a determinant of climbing performance in high-level sport climbers. Eur J Appl Physiol, 2009; 107: 517-525

Fanchini M, Violette F, Impellizzeri FM, Maffiuletti NA. Differences in climbing-specific strength between boulder and lead rock climbers. J Strength Cond Res, 2013; 27: 310-314

Ferguson RA, Brown MD. Arterial blood pressure and forearm vascular conductance responses to sustained and rhythmic isometric exercise and arterial occlusion in trained rock climbers and untrained sedentary subjects. Eur J Appl Physiol Occup Physiol, 1997; 76: 174-180

Giles LV, Rhodes EC, Taunton JE. The physiology of rock climbing. Sports Med, 2006; 36: 529-545

Grant S, Hasler T, Davies C, Aitchison TC, Wilson J, Whittaker A. A comparison of the anthropometric, strength, endurance and flexibility characteristics of female elite and recreational climbers and nonclimbers. J Sports Sci, 2001; 19: 499-505

MacLeod D, Sutherland DL, Buntin L, Whitaker A, Aitchison T, Watt I, Bradley J, Grant S. Physiological determinants of climbing-specific finger endurance and sport rock climbing performance. J Sports Sci, 
2007; 25: 1433-1443

Magiera A, Roczniok R, Maszczyk A, Czuba M, Kantyka J, Kurek P. The Structure of Performance of a Sport Rock Climber. J Hum Kinet, 2013; 36: 107-117

Mermier CM, Janot JM, Parker DL, Swan JG. Physiological and anthropometric determinants of sport climbing performance. Br J Sports Med, 2000; 34: 359-365; discussion 366

Michailov M, Mladenov L, Schoffl V. Anthropometric and strength characteristics of world-class boulderers. Medicina Sportiva, 2009: 231-238

Philippe M, Wegst D, Müller T, Raschner C, Burtscher M. Climbing-specific finger flexor performance and forearm muscle oxygenation in elite male and female sport climbers. Eur J Appl Physiol, 2012; 112: 2839-2847

Quaine F, Vigouroux L. Maximal resultant four fingertip force and fatigue of the extrinsic muscles of the hand in different sport climbing finger grips. Int J Sports Med, 2004; 25: 634-637

Rokowski R, Tokarz R. Energetic motor abilities in rock climbing (on-sight performance). Antropomotoryka, 2007: 81-91

Ruchlewicz T, Chwała W, Staszkiewicz R. Strength parameters of selected muscle groups in rock climbers. Biology of Sport, 1997; 14: 113-117

Schöffl VR, Einwag F, Strecker W, Schöffl I. Strength measurement and clinical outcome after pulley ruptures in climbers. Med Sci Sports Exerc, 2006; 38: 637-643

Schweizer A. Biomechanical properties of the crimp grip position in rock climbers. J Biomech, 2001; 34: 217223

Schweizer A, Furrer M. Correlation of forearm strength and sport climbing performance. Isokinetics and Exercise Science, 2007; 15: 211-216

Sheel A. Physiology of sport rock climbing. Br J Sports Med, 2004; 38: 355-359

Staszkiewicz R, Ruchlewicz T, Szopa J. Handgrip strength and selected endurance variables. Journal of Human Kinetics, 2002: 29-42

Watts P, Jensen R, Gannon E, Kobeinia R, Maynard J, Sansom J. Forearm EMG During Rock Climbing Differs from EMG During Handgrip Dynamometry. International Journal of Exercise Science, 2008; 1

Watts PB. Physiology of difficult rock climbing. Eur J Appl Physiol, 2004; 91: 361-372

Watts PB, Martin DT, Durtschi S. Anthropometric profiles of elite male and female competitive sport rock climbers. J Sports Sci, 1993; 11: 113-117

\section{Corresponding author:}

\section{Arkadiusz Stanula}

Department of Sports Training,

The Jerzy Kukuczka Academy of Physical Education,

Katowice, Poland.

E-mail: a.stanula@awf.katowice.pl 